\title{
What Are the Most Challenging Aspects of Inflammatory Bowel Disease? An International Survey of Gastroenterologists Comparing Developed and Developing Countries
}

\author{
Richard B. Gearry ${ }^{a}$ Andrew M. McCombie ${ }^{a}$ Morten Vatn ${ }^{b}$ David T. Rubin ${ }^{c}$ \\ Flavio Steinwurz ${ }^{d}$ Edward V. Loftus ${ }^{e}$ Wolfgang Kruis ${ }^{f}$ Curt Tysk $^{g}$ \\ Jean-Frederic Colombel ${ }^{\text {h }}$ Siew C. Ng ${ }^{i}$ Gert Van Assche ${ }^{j} \quad$ Charles N. Bernsteink \\ International Organization for the Study of Inflammatory Bowel Diseases and the \\ World Gastroenterology Organization

\begin{abstract}
aDepartment of Medicine, University of Otago, Christchurch, New Zealand; b Institute of Clinical Medicine, University of Oslo, Oslo, Norway; Inflammatory Bowel Disease Center, University of Chicago Medicine, Chicago, IL, USA; ${ }^{\mathrm{d} D e p a r t m e n t}$ of Gastroenterology, Hospital Israelita Albert Einstein, Sao Paulo, Brazil; eDivision of Gastroenterology and Hepatology, Mayo Clinic, Rochester, MN, USA; fDepartment of Internal Medicine, University of Cologne,

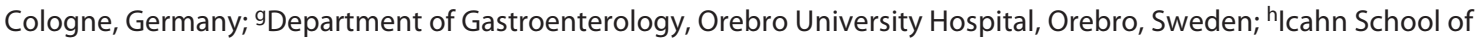
Medicine at Mount Sinai, New York, NY, USA; 'Department of Medicine and Therapeutics, Institute of Digestive Disease, State Key Laboratory of Digestive Diseases, LKS Institute of Health Science, Chinese University of Hong Kong, Hong Kong Special Administrative Region, Hong Kong, Hong Kong SAR; 'Division of Gastroenterology, G UZ Gasthuisberg, Leuven, Belgium; 'Kection of Gastroenterology, Max Rady School of Medicine and University of Manitoba IBD Clinical and Research Centre, Winnipeg, MB, Canada
\end{abstract}

\section{Keywords}

Challenges · Crohn's disease · Ulcerative colitis ·

Inflammatory bowel diseases

\begin{abstract}
Background and Aims: As inflammatory bowel disease (IBD) becomes more prevalent, the challenges that gastroenterologists face in managing these patients evolve. We aimed to describe the most important challenges facing gastroenterologists from around the world and compare these between those working in developed and developing countries. Methods: An online questionnaire was developed, and
\end{abstract}

karger@karger.com www.karger.com/iid

Karger $\stackrel{\text { ' }}{5}$

GOPEN ACCESS
(C) 2021 The Author(s)

Published by S. Karger AG, Basel

This is an Open Access article licensed under the Creative Commons Attribution-NonCommercial-4.0 International License (CC BY-NC) (http://www.karger.com/Services/OpenAccessLicense), applicable to the online version of the article only. Usage and distribution for commercial purposes requires written permission. a link distributed to gastroenterologists. Data were analyzed descriptively using Friedman and Wilcoxon matched-pair signed rank tests to compare rankings for responses. MannWhitney $U$ tests were used to compare rankings between responses from gastroenterologists from developed and developing countries. Lower scores reflected greater challenges. Results: Of 872 who started, 397 gastroenterologists (45.5\%) completed the survey. Respondents represented 65 countries (226 [56.9\%] from developed countries). Overall, the challenge ranked most important (smallest number) was increasing IBD prevalence (13.6\%). There were significant differences in mean ranking scores for many simple aspects of care for those from developing countries compared to 
providers from developed countries, such as access to simple IBD treatments ( 5.52 vs. $6.02, p=0.01$ ), access to anti-TNF drugs including dose escalation (3.33 vs. $3.93, p<0.01$ ), access to good stoma care ( 2.57 vs. $3.03, p<0.001)$, access to therapeutic drug monitoring (1.47 vs. $1.84, p<0.001)$, and access to care for people from low socioeconomic status ( 2.77 vs. $3.37, p<0.001)$. Conclusions: Increasing IBD prevalence is seen by gastroenterologists as the greatest challenge facing them. There are significant differences between the IBD challenges facing gastroenterologists from developed and developing countries that reflect inequities in access to health care.

(C) 2021 The Author(s)

Published by S. Karger AG, Basel

\section{Introduction}

The inflammatory bowel diseases (IBDs), Crohn's disease and ulcerative colitis, are complex diseases of increasing worldwide prevalence and poorly understood etiology $[1,2]$. With no known cure, the burden of disease facing health-care workers and society is increasing, leading to increased morbidity for patients and their families and increased costs for health-care systems. This phenomenon has been termed "compound prevalence," reflecting the increasing incidence worldwide, with few IBD patients dying from their disease [3].

There are considerable differences in the epidemiology of IBD worldwide [4]. Incidence rates vary significantly between countries and over time. Phenotype and presentations also may differ, albeit modestly, between populations around the world [5,6]. Additionally, health-care systems, including access to investigation, therapy, and health-care professionals, are also different [7].

Acknowledging these differences, organizations such as the World Gastroenterology Organisation (WGO) have developed treatment guidelines taking a cascade approach, tailoring advice on the best management to the resources of different health-care systems $[7,8]$. Other organizations have set IBD research agendas based on expert opinion, often with input from patients $[9,10]$. However, to our knowledge, the challenges facing gastroenterologists as they care for IBD patients have not been studied, nor have they been compared between developed and developing countries. In a collaboration between the International Organization for the Study of IBD (IOIBD) and the WGO, we aimed to survey a range of gastroenterologists from around the world and compare their opinions of the greatest challenges facing them in their practice.

Challenges for Gastroenterologists

Treating IBD

\section{Materials and Methods}

The Globalization Cluster of IOIBD planned the study taking into account the global reach of its members. Collaboration was sought from the WGO to ensure that global representation was accessed.

Survey Design

The survey was designed to collect a range of background information, including geographical data on country and city of practice, and practice data including public or private, academic, and IBD specialist. The domains of challenging issues that were to be investigated included IBD epidemiology, etiology, diagnostics, medical and surgical treatment, multidisciplinary care, disease activity, monitoring of treatment, risks of IBD, access to medical care, and the direct impact of IBD on patients. Design of the questions and the answers to be ranked was performed iteratively with expert opinion from the authors (all IBD experts) based on clinical and research experience. The online survey was designed and run from the QuestionPro platform and was only available in English.

Participants were asked to rank predetermined responses in each domain from most challenging (1) to least challenging (maximum number of responses). Thus, the lower the numerical ranking given, the higher the importance attributed to the challenge. For each participant, the greatest challenge from each domain was listed in the final question. The participants then chose the greatest overall challenge that they had ranked across all of the domains.

\section{Participant Recruitment}

The aim was to recruit as many gastroenterologists from as many countries around the world as possible. In order to do this, members of IOIBD and the WGO contacted national gastroenterology organizations and societies from around the world. Each was asked to distribute an invitation to gastroenterologists to participate in the survey. Follow-up invitations were sent to national organizations and societies to encourage participation. Participants were asked to respond to the questionnaire based on their own practices.

\section{Statistics}

The data were analyzed descriptively. Responses were ranked and compared between those from developed and developing countries [11]. Friedman tests were used to provide an overall comparison of the ranking of responses within each domain. The Wilcoxon matched-pair signed rank test was used to compare individual rankings of responses within each domain. Mann-Whitney $U$ tests were used to compare rankings from developed and developing countries. $p$ values of $<0.05$ were considered to be statistically significant.

\section{Results}

Eight hundred seventy-two participants commenced the survey, with 397 completing it (45.5\% completion rate). The characteristics of the participants are given in Table 1. Participants came from 65 countries (online suppl. Table 1; for all online suppl. material, see www.karger.

Inflamm Intest Dis 2021;6:78-86 
com/doi/10.1159/000512310), with the highest number of responses from Brazil (44), Greece (33), Canada (28), and India (22). More respondents came from developed than developing countries, and most worked in academic or referral centers with a high proportion of IBD specialists responding to the questionnaire.

Summary data ranking the challenges in each domain, including a comparison in mean rankings between gastroenterologists from developed and developing countries, are shown in Table 2. Additionally, the number and proportion of respondents ranking each of the areas as most challenging are also displayed for the entire group and divided into respondents from developed and developing countries.

\section{Epidemiology of IBD}

Increasing IBD prevalence was ranked as the greatest challenge in the IBD epidemiology domain (mean rank $2.44 / 6, p<0.001$ vs. all other responses). This was also reflected in the high proportion of respondents (46\%) who ranked this challenge first, compared to other challenges listed in the epidemiology domain. There were no significant differences between respondents from developed and developing countries for epidemiological variables, except for issues specific to IBD in pregnancy where this was ranked significantly more challenging in developed countries (mean ranking 3.17 vs. $3.51, p=0.02$ ).

\section{Etiology of IBD}

Understanding the gut microbiome was ranked statistically significantly more challenging than the other issues (mean rank 2.72/4, $p<0.05$ vs. all other responses). Additionally, there were statistically significant different rankings between respondents from developed and developing countries for IBD genetics and epigenetics (ranked more important for developing countries [mean ranking 2.48 vs. $3.16, p<0.001]$ ) and environmental risk factors for IBD (ranked more important for developed countries [mean ranking 2.27 vs. $2.68, p<0.001$ ]). These differences in mean rankings between respondents from developed and developing countries were reflected in the proportions of respondents ranking these challenges as most important (environmental risk factors [33 and 22\%, respectively] and genetic factors [ 13 and $31 \%$, respectively]).

\section{Diagnosis of IBD}

IBD knowledge and diagnostics in primary care (general practice) had the highest mean ranking in the diagnosis domain (mean rank 2.02/4, $p<0.001$ vs. all other
Table 1. Characteristics of questionnaire participants

Frequency (\%)

$\begin{array}{lr}\text { Developed versus developing countries } & \\ \text { Developed } & 226(56.9) \\ \text { Developing } & 171(43.1) \\ \text { Public versus private } & 13(3.3) \\ \text { Not applicable } & 151(38.0) \\ \text { Work in both } & 59(14.9) \\ \text { Work in private practice only } & 174(43.8) \\ \text { Work in public practice only } & \\ \text { Academic versus community practice } & 205(51.6) \\ \text { Work in an academic/referral center only } & 114(28.7) \\ \text { Work in both } & 78(19.6) \\ \text { Work in community practice only } & \\ \text { IBD specialist or generalist } & 208(52.4) \\ \text { General gastroenterologist } & 189(57.6) \\ \text { IBD specialist } & \end{array}$

IBD, inflammatory bowel disease.

responses). Over half of all respondents also ranked this as the single most important challenge (210/397 [53\%]) in the diagnosis domain. There were no statistically significant differences in rankings between respondents from developed and developing countries in this domain.

\section{Medical and Surgical Treatment of IBD}

Access to an IBD specialist for IBD treatment (mean rank 3.09/7, $p<0.05$ vs. other responses except access to non-anti-TNF biologics/small molecules and access to an IBD surgeon) had the highest mean ranking in this domain. However, the challenge identified by the most respondents as the greatest was access to non-anti-TNF biologics/new small molecules (126/397 [32\%]). There were significant differences between respondents from developed and developing countries for a number of challenges. Those from developed countries ranked access to an IBD specialist (mean ranking 2.90 vs. 3.34, $p=$ 0.012 ) and access to an IBD surgeon (mean ranking 3.08 vs. $3.57, p=0.006$ ) significantly more challenging than those from developing counties. Those from developing countries ranked access to simple IBD treatments (e.g., 5-ASA, steroids, and immunomodulators) (mean ranking 5.52 vs. $6.02, p=0.01$ ) and access to anti-TNF drugs including dose escalation (mean ranking 3.33 vs. 3.93, $p<0.01$ ) as the most challenging aspects of IBD in this domain.
Gearry et al. 
Table 2. Mean rank of challenges in each domain, divided into rankings from gastroenterologists from developed and developing countries

\begin{tabular}{|c|c|c|c|c|c|c|}
\hline Challenge & $\begin{array}{l}\text { Mean rank } \\
\text { (overall) }\end{array}$ & $\begin{array}{l}\text { Mean rank } \\
\text { (developed) }\end{array}$ & $\begin{array}{l}\text { Mean rank } \\
\text { (developing) }\end{array}$ & $\begin{array}{l}\text { Number ranking } \\
\text { first (\%) }\end{array}$ & $\begin{array}{l}\text { g Number ranking } \\
\text { first, developed (\%) }\end{array}$ & $\begin{array}{l}\text { Number ranking } \\
\text { first, developing (\%) }\end{array}$ \\
\hline \multicolumn{7}{|l|}{ Epidemiology of IBD } \\
\hline Increasing prevalence of IBD & $2.44^{* * *}$ & 2.56 & 2.29 & $181(46)$ & $100(45)$ & $81(47)$ \\
\hline Issues specific to IBD in pregnancy & 3.32 & $3.17^{\mathrm{a}}$ & $3.51^{\mathrm{a}}$ & $38(10)$ & $25(11)$ & $13(8)$ \\
\hline Being able to explain to people why they have IBD & 3.39 & 3.49 & 3.25 & $85(21)$ & $47(21)$ & $38(22)$ \\
\hline Issues specific to pediatric IBD & 3.55 & 3.60 & 3.49 & $54(14)$ & $28(12)$ & $26(15)$ \\
\hline Issues specific to geriatric IBD & 3.71 & 3.62 & 3.83 & $27(7)$ & $16(7)$ & $11(6)$ \\
\hline Issues specific to IBD in specific ethnic groups & 4.59 & 4.56 & 4.63 & $12(3)$ & $10(4)$ & $2(1)$ \\
\hline \multicolumn{7}{|l|}{ Etiology of IBD } \\
\hline Understanding the gut microbiome in IBD & $2.72^{* *}$ & 2.06 & 2.24 & $106(27)$ & $63(28)$ & $43(25)$ \\
\hline Understanding environmental risk factors for IBD & 3.05 & $2.27^{\mathrm{c}}$ & $2.68^{\mathrm{c}}$ & $111(28)$ & $75(33)$ & $38(22)$ \\
\hline Understanding the mechanisms of inflammation in IBD & 3.18 & 2.50 & 2.60 & $96(24)$ & $59(26)$ & $37(22)$ \\
\hline Understanding genetics/epigenetics of IBD & 3.54 & $3.16^{\mathrm{c}}$ & $2.48^{\mathrm{c}}$ & $82(21)$ & $29(13)$ & $53(31)$ \\
\hline \multicolumn{7}{|l|}{ Diagnosis of IBD } \\
\hline IBD knowledge and diagnostics in primary care (general practice) & $2.02^{* * *}$ & 2.05 & 1.96 & $210(53)$ & $114(50)$ & $96(56)$ \\
\hline Access to gastroenterologist for diagnosis & 2.56 & 2.57 & 2.56 & $62(16)$ & $36(16)$ & $26(15)$ \\
\hline Access to endoscopy/imaging/pathology for diagnosis & 2.68 & 2.70 & 2.65 & $85(21)$ & $48(22)$ & $37(22)$ \\
\hline IBD knowledge and diagnostics in secondary care (gastroenterology) & 2.74 & 2.68 & 2.82 & $40(10)$ & $28(12)$ & $12(7)$ \\
\hline \multicolumn{7}{|l|}{ Medical and surgical treatment of IBD } \\
\hline Access to IBD specialist for IBD treatment & $3.09^{*}$ & $2.90^{\mathrm{a}}$ & $3.34^{\mathrm{a}}$ & $96(24)$ & $61(27)$ & $35(20)$ \\
\hline Access to non-anti-TNF biologics/new small molecules & 3.23 & 3.30 & 3.14 & $126(32)$ & $60(27)$ & $66(39)$ \\
\hline Access to IBD surgeon for IBD treatment & 3.29 & $3.08^{\mathrm{b}}$ & $3.57^{\mathrm{b}}$ & $73(18)$ & $50(22)$ & $23(13)$ \\
\hline Access to anti-TNF, including dose escalation & 3.67 & 3.93 & 3.33 & $35(9)$ & $15(7)$ & $20(12)$ \\
\hline Access to gastroenterologist for IBD treatment & 4.09 & 3.97 & 4.25 & $57(14)$ & $37(16)$ & $20(12)$ \\
\hline Access to general surgeon for IBD treatment & 4.82 & 4.81 & 4.85 & $0(0)$ & $0(0)$ & $0(0)$ \\
\hline $\begin{array}{l}\text { Access to simple IBD treatments (5-ASA, steroid, and } \\
\text { immunomodulators) }\end{array}$ & 5.80 & $6.02^{\mathrm{b}}$ & $5.52^{\mathrm{b}}$ & $10(3)$ & $3(1)$ & $7(4)$ \\
\hline
\end{tabular}

\section{Multidisciplinary IBD care}

Access to psychological care

Access to IBD nursing

Access to a dietitian

Access to good stoma care

$2.17^{* * *} \quad 1.94$

$2.36 \quad 2.40$

$2.64 \quad 2.62$

$2.84 \quad 3.03$

Monitoring treatment and safety

Access to immunomodulator and biologic therapeutic drug monitoring

Access to newer markers of IBD activity (e.g., fecal calprotectin)

Access to vaccination for those on immunomodulators/biologics

Access to basic laboratory tests

Complications of IBD and its treatment

Risk of IBD-associated infections

Risk of IBD-associated cancer

Risk of poor nutrition due to IBD

Risk of IBD-associated thromboembolic events

$\begin{array}{lllccc}1.68^{* * *} & 1.84^{\mathrm{c}} & 1.47^{\mathrm{c}} & 207(52) & 95(42) & 112(65) \\ 2.17 & 2.16 & 2.19 & 77(19) & 50(22) & 27(16) \\ 2.44 & 2.25^{\mathrm{c}} & 2.70^{\mathrm{c}} & 93(23) & 72(32) & 21(12) \\ 3.70 & 3.74 & 3.64 & 20(5) & 9(4) & 11(6)\end{array}$

\begin{tabular}{|c|c|c|c|c|c|c|}
\hline Risk of IBD-associated thromboembolic events & 3.31 & 3.31 & 3.30 & $24(6)$ & $12(4)$ & $12(6)$ \\
\hline \multicolumn{7}{|l|}{ Logistics of IBD care } \\
\hline Timely clinical assessment of unwell patients & $2.70^{*}$ & $2.48^{\mathrm{c}}$ & $2.98^{\mathrm{c}}$ & $92(23)$ & $71(31)$ & $21(12)$ \\
\hline IBD management in primary care & 2.82 & 2.86 & 2.75 & $104(26)$ & $53(23)$ & $51(30)$ \\
\hline Care for those in geographically remote locations & 2.90 & 2.91 & 2.89 & $70(18)$ & $42(19)$ & $28(16)$ \\
\hline Access to IBD care for people of low socioeconomic status & 3.11 & $3.37^{\mathrm{c}}$ & $2.77^{\mathrm{c}}$ & $86(22)$ & $36(16)$ & $50(29)$ \\
\hline Access to telemedicine/e-medicine & 3.47 & $3.38^{\mathrm{a}}$ & $3.60^{\mathrm{a}}$ & $45(11)$ & $24(11)$ & $21(12)$ \\
\hline \multicolumn{7}{|l|}{ Impact of IBD symptoms } \\
\hline Perianal symptoms in IBD patients & $2.91^{* * *}$ & 2.81 & 3.05 & $141(36)$ & $86(38)$ & $55(32)$ \\
\hline Increased bowel motion frequency due to IBD & 3.61 & $4.14^{\mathrm{c}}$ & $2.92^{\mathrm{c}}$ & $80(20)$ & $25(11)$ & $55(32)$ \\
\hline IBD-related pain & 3.64 & 3.62 & 3.67 & $38(10)$ & $23(10)$ & $15(9)$ \\
\hline IBD patient fatigue & 3.68 & $3.12^{\mathrm{c}}$ & $4.42^{\mathrm{c}}$ & $89(22)$ & $72(32)$ & $17(10)$ \\
\hline Low mood associated with IBD & 4.20 & $3.98^{\mathrm{b}}$ & $4.50^{\mathrm{b}}$ & $24(6)$ & $14(6)$ & $10(6)$ \\
\hline Traditional extraintestinal manifestations of IBD & 4.45 & $4.73^{\mathrm{b}}$ & $4.08^{\mathrm{b}}$ & $24(6)$ & $5(2)$ & $19(11)$ \\
\hline Sleep disturbance caused by IBD & 5.51 & $5.61^{\mathrm{a}}$ & $5.36^{\mathrm{a}}$ & $2(1)$ & $2(1)$ & $0(0)$ \\
\hline
\end{tabular}

Challenges for Gastroenterologists

Treating IBD
Inflamm Intest Dis 2021;6:78-86

DOI: $10.1159 / 000512310$ 
Table 2 (continued)

\begin{tabular}{|c|c|c|c|c|c|c|}
\hline Challenge & $\begin{array}{l}\text { Mean rank } \\
\text { (overall) }\end{array}$ & $\begin{array}{l}\text { Mean rank } \\
\text { (developed) }\end{array}$ & $\begin{array}{l}\text { Mean rank } \\
\text { (developing) }\end{array}$ & $\begin{array}{l}\text { Number ranking } \\
\text { first (\%) }\end{array}$ & $\begin{array}{l}\text { Number ranking } \\
\text { first, developed (\%) }\end{array}$ & $\begin{array}{l}\text { Number ranking } \\
\text { first, developing (\%) }\end{array}$ \\
\hline \multicolumn{7}{|l|}{ Broader impact of IBD } \\
\hline The impact of IBD on work & $1.98^{* * *}$ & 1.92 & 2.05 & $174(44)$ & $104(46)$ & $70(41)$ \\
\hline The impact of IBD on relationships & 2.77 & $2.57^{\mathrm{c}}$ & $3.04^{\mathrm{c}}$ & $68(17)$ & $46(20)$ & $22(13)$ \\
\hline The impact of IBD on education & 3.27 & $3.12^{\mathrm{a}}$ & $3.47^{\mathrm{a}}$ & $57(14)$ & $33(15)$ & $24(14)$ \\
\hline The impact of IBD on personal finances & 3.35 & $3.74^{\mathrm{c}}$ & $2.84^{\mathrm{c}}$ & $50(13)$ & $14(6)$ & $36(21)$ \\
\hline The impact of IBD on family relationships & 3.63 & 3.65 & 3.60 & $48(12)$ & $29(13)$ & $19(11)$ \\
\hline
\end{tabular}

Within every domain, overall comparisons of rankings were statistically significantly different $(p<0.001$, Friedman test). The frequency of top-ranked challenges is also displayed within each domain. IBD, inflammatory bowel disease. ${ }^{*} p<0.05$. $^{* *} p<0.01$. ${ }^{* * *} p<0.001$, Wilcoxon matched-pair signed rank test. ${ }^{\mathrm{a}} p<0.05 .{ }^{\mathrm{b}} p<0.01 .{ }^{\mathrm{c}} p<0.001$, Mann-Whitney $U$ test.

\section{Multidisciplinary IBD Care}

Overall, access to psychological care for IBD patients was seen as the greatest challenge across all respondents in this domain (mean rank 2.17/4, $p<0.001$ vs. all other responses except access to IBD nurse). This was significantly more so in respondents from developed countries (mean ranking 1.94 vs. 2.46, $p<0.001$ ). This was also reflected in both the overall number of respondents who ranked access to psychological care as the greatest challenge (142/397 [36\%]) and the difference between respondents from developed and developing countries (99/226 [44\%] and 43/171 [25\%], respectively). Access to good stoma care was ranked as being a more challenging issue for those from developing than from developed countries (mean ranking 2.57 vs. $3.03, p<0.001$ ).

\section{Monitoring Treatment and Safety}

Access to immunomodulator and biologic drug monitoring was the most challenging issue in this domain across all respondents (mean rank 1.68/4, $p<0.001$ vs. all other responses, most challenging issue in 207/397 [52\%] of respondents) but significantly more so for those from developing countries (mean ranking 1.47 vs. 1.84, $p<$ 0.001). On the other hand, respondents from developed countries ranked access to vaccination as the most challenging issue in this domain (mean ranking 2.25 vs. 2.70 , $p<0.001)$.

\section{Complications of IBD and Its Treatment}

The risk of IBD-associated infections was seen as the greatest challenge by all respondents (mean rank 1.93/4, $p<0.001$ vs. all other responses, most challenging issue in 161/397 [41\%] of respondents). Those from developed countries were more likely to rank the risk of IBD-associated cancers as more challenging than those from de- veloping countries (mean ranking 2.21 vs. $2.46, p=$ $0.013)$.

\section{Logistics of IBD Care}

Timely clinical assessment of unwell patients was ranked the most challenging aspect of IBD care in this domain (mean rank 2.70/5, $p<0.05$ for other responses except IBD management in primary care and care for those in geographically remote locations), significantly more so for those from developed countries (mean ranking 2.48 vs. $2.98, p<0.001$, most challenging issue in $71 / 226$ [31\%] vs. $21 / 171$ [12\%] of respondents). Respondents from developed countries were also more likely to rank access to telemedicine/e-medicine as a more challenging issue than those from developing countries (mean ranking 3.38 vs. $3.60, p=0.05$ ). Respondents from developing countries were more likely to rank access to IBD care for people from low socioeconomic status as a more challenging problem than those from developed countries (mean ranking 2.77 vs. $3.37, p<0.001$, most challenging issue in 50/171 [29\%] vs. 36/226 [16\%] of respondents).

\section{Impact of IBD Symptoms}

Perianal symptoms in IBD patients were ranked across all respondents as the most challenging aspects of IBD care (mean rank 2.91/7, $p<0.001$ vs. other responses, most challenging issue in 141/397 [36\%] of respondents). However, those from developed countries ranked fatigue (mean ranking 3.12 vs. $4.42, p<0.001$, most challenging issue in $72 / 226$ [32\%] vs. $17 / 171$ [10\%] of respondents) and low mood (mean ranking 3.98 vs. $4.50, p=0.003$ ) associated with IBD as the most challenging aspects of IBD care. Respondents from developing countries ranked increased bowel motion frequency (mean ranking $2.92 \mathrm{vs.}$
Gearry et al. 
Fig. 1. Five most challenging issues for gastroenterologists in IBD globally. IBD, inflammatory bowel disease.

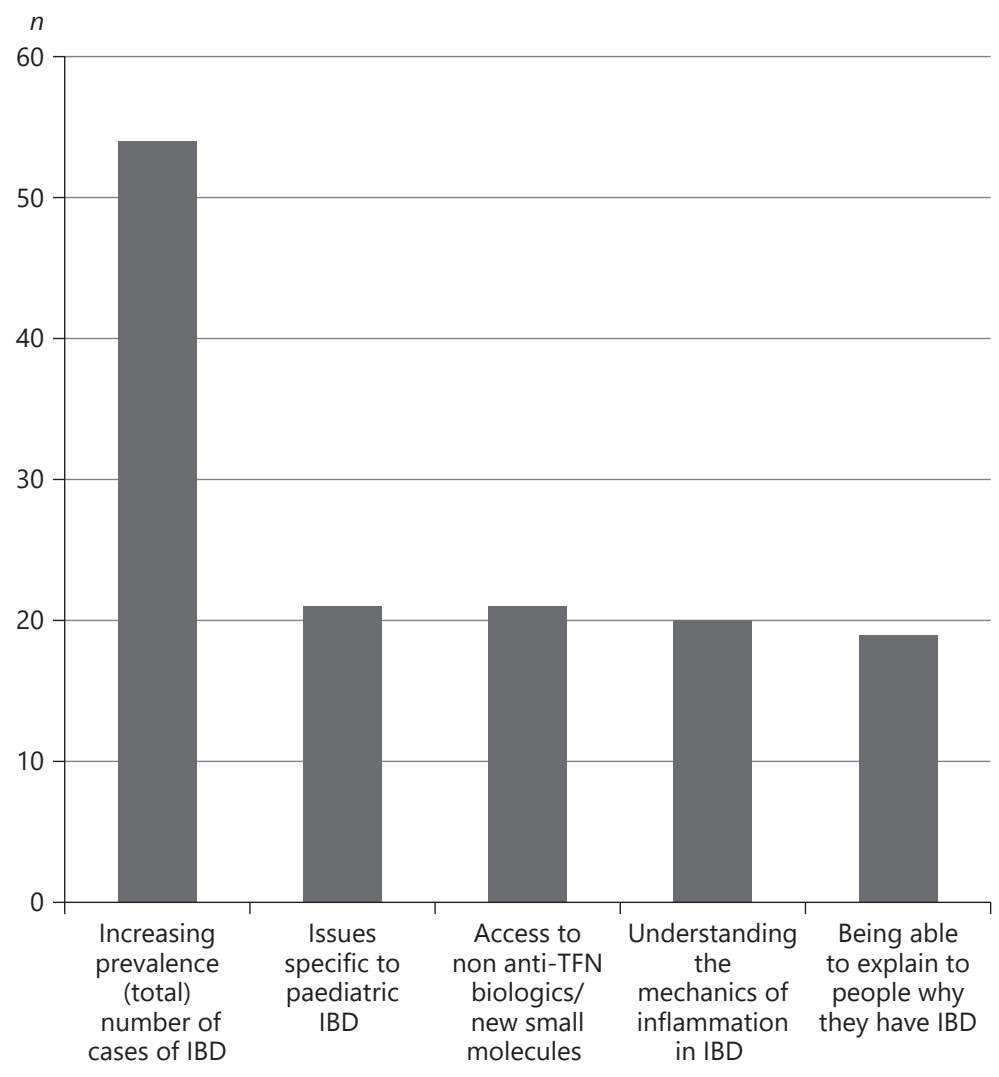

$4.14, p<0.001$, most challenging issue in $55 / 171$ [32\%] vs. $25 / 226$ [11\%] of respondents), traditional extraintestinal manifestations (mean ranking 4.08 vs. $4.73, p=0.002$ ), and sleep disturbance (mean ranking 5.36 vs. $5.61, p=$ $0.025)$ significantly more challenging than those from developed countries.

\section{Broader Impact of IBD}

The impact of IBD on the ability to work was the greatest challenge ranked by all respondents (mean rank $1.98 / 5, p<0.0001$ vs. other responses, most challenging issue in 174/397 [44\%] of respondents). Those from developed countries ranked the impact of IBD on relationships (mean ranking 2.57 vs. 3.04, $p<0.001$ ) and education (mean ranking 3.12 vs. $3.47, p=0.011$ ) significantly more challenging than those from developing countries. Respondents from developing countries ranked the impact of IBD on personal finances significantly more challenging than those from developed countries (mean ranking 2.84 vs. $3.74, p<0.001$, most challenging issue in $36 / 171$ [21\%] vs. $14 / 226$ [6\%] of respondents).

Challenges for Gastroenterologists Treating IBD

\section{Overall Most Challenging Issues in IBD}

As the respondents completed the questionnaire, the issue that they ranked most significant in each domain was inserted into the final question for each individual. This question asked the respondents to rank their most challenging issue across the entire questionnaire. As each of the respondents had a different set of answers for this final question, based on their top responses from each domain, there was a wide range of responses. However, the most common response as the most challenging issue was the increasing prevalence of IBD (Fig. 1).

\section{Discussion}

As IBD incidence continues to increase, leading to more patients requiring investigation and treatment, it is important for gastroenterologists to reflect on the issues that are most challenging in the care of these patients. To our knowledge, this is the first time that gastroenterologists from around the world have reported the challenges 
they face and the first time that these challenges have been compared between developed and developing countries.

Overall, across all of the domains, the issue reported to be most challenging by gastroenterologists was the increasing prevalence of IBD. Of the 51 issues that were ranked throughout the questionnaire, this was viewed as the most challenging by 54/379 (13.6\%) respondents. No other issue was ranked as the most challenging by more than 21/297 (5.2\%) of respondents. There is a plethora of evidence that worldwide the IBD prevalence continues to increase, especially due to increasing rates of IBD in developing countries. Data from the most populous countries in the world such as China [12], India [13], and Brazil [14] confirm that incidence is increasing, driving up the prevalence of IBD. Although the incidence of IBD is significantly lower in developing countries, small increases in incidence across large populations will lead to a large increase in the absolute number of people with IBD in these regions. Such an increase will have significant implications for health-care resource allocation, including training of the health workforce and access to diagnostic testing and treatment. This was also reflected in responses to challenges in the IBD diagnostics domain, where IBD knowledge and diagnostics in primary care was identified as the greatest challenge across all respondents.

Although we were unable to determine the reasons why increasing IBD prevalence was ranked as the greatest challenge by gastroenterologists, resource constraints in their own practices and the health-care systems they work in may limit the ability for IBD patients to receive the best care. In developing countries, this is likely to be an even greater problem.

There were a number of significant differences in the ranking of challenges between respondents from developed and developing countries. In general, these differences reflect unequal access to diagnostic testing and medical and surgical therapies between these regions.

For example, respondents from developing countries ranked access to simple IBD treatments and access to anti-TNF drugs more challenging than those from developed countries, reflecting the significant differences in access to treatments around the world. While gastroenterologists in some countries have access to new biologic agents and small molecules, gastroenterologists in other countries struggle to access 5-ASA, steroids, and immunomodulators. Anti-TNF biologics are not readily accessible to a significant proportion of IBD patients around the world. These inequalities in access to treatment are likely to lead to poorer outcomes for IBD patients living in developing countries, in part because gastroenterolo- gists will not be able to treat IBD patients according to international guidelines.

Other challenges that were more commonly reported by gastroenterologists from developing countries included access to IBD care for people from low socioeconomic groups. This also likely reflects health-care systems, where there may not be universal health care or where such care is less comprehensive. Inequity of access to health care within developing countries is likely to impact negatively on those from lower socioeconomic groups. Gastroenterologists from developed countries were more likely to find e-medicine and telemedicine to be challenging, both models of care that may be less likely to be available in developing countries, although may be of even more benefit in those countries if they were available. Similar differences were also seen between respondents from developing and developed countries regarding the direct impact of IBD on IBD patients.

Although all respondents ranked the impact of IBD on the ability to work as being the most challenging issue, respondents from developing countries were more likely to rank the impact of IBD on personal finances. This may reflect a lack of or inadequate social security in some developing countries. Respondents from developed countries were more likely to report the impact of IBD being a greater challenge on relationships and education. It would appear that gastroenterologists from developed countries see challenges in their patients thriving with IBD, while those from developing countries see challenges in financially surviving.

While the management of perianal symptoms in Crohn's disease patients was consistently the most challenging symptom to manage, those in developing countries reported that increased bowel motion frequency, traditional extraintestinal manifestations, and sleep disturbance were the most challenging symptoms. This may reflect the lack of access to treatments that are most effective at controlling these symptoms, especially bowel motion frequency. On the other hand, the non-gastrointestinal symptoms of fatigue and low mood were more challenging for gastroenterologists from developed countries, perhaps reflecting that access to treatments for gastrointestinal symptoms was less of a problem.

There are a number of limitations to the current study. First, the sample size of 397 respondents is small, given that the potential study population includes all gastroenterologists in the world, and therefore, we could not assess with statistical confidence differences between individual countries. However, the range of respondents from 69 countries, including a high proportion from developing 
countries, is unique in its breadth of recruitment among international gastroenterologists. As might be expected, the proportion of respondents who work in an academic or a referral center was high, as was the proportion of respondents who classify themselves as IBD specialists, reflecting gastroenterologists who are more likely to take part in IBD research. However, these respondents may be more likely than others to understand the challenges of IBD care in their country. Further, we could not determine the number of gastroenterologists requested to complete the survey, so we cannot describe an overall response rate. The questionnaire was only available in English, which will have excluded non-English speakers from completing the survey. While there was a wide range of countries represented by the respondents, the variability of therapeutic options and health-care coverage in each country was not addressed or included, so this could not be assessed as a confounder or predictor of differences. It is possible that there are other challenging issues in IBD care that were not given as options in the questionnaire. The wider author group used an iterative process to develop the questionnaire, but most of the investigators came from developed countries, which could have affected the design of the questionnaire.

Finally, the COVID-19 pandemic that has led to millions of the world's population being infected and, at present, several hundred thousand dead could not have been predicted when this survey was undertaken. This study reflects a pre-COVID-19 view of gastroenterologists and the challenges they face in managing IBD. Given the seismic changes to health care that have occurred in 2020 , it is likely that managing IBD patients in the setting of the COVID-19 pandemic would currently rank as one of the greatest challenges facing gastroenterologists managing IBD patients. This is particularly the case in our IBD patients who are immunosuppressed and are probably at greater risk of poor outcomes from SARS-CoV-2 infection [15]. However, issues of inequity and disparate health-care resources are likely to have a significant impact on the outcomes of SARS-CoV-2 infections in IBD patients from developed and developing countries.

\section{Conclusions}

A large and diverse group of international gastroenterologists have reported on the most challenging issues they face in the care of patients with IBD. We have shown that increasing IBD prevalence is the most challenging issue facing gastroenterologists worldwide. Furthermore, there are significant differences in perceived challenges between gastroenterologists working in developing compared with developed countries, many of which reflect differential access to health care between countries. While the IBD clinical and research community must continue to strive for breakthroughs in IBD treatment, we should also remember that improving the care for IBD patients from developing countries will reduce inequities and lead to significant benefits for IBD patients globally. Finally, directly inquiring of gastroenterologists what their perceived challenges are will help focus on solving the specific challenges in the different jurisdictions.

\section{Acknowledgements}

The authors would like to acknowledge the International Organization for the Study of Inflammatory Bowel Diseases (IOIBD) and the World Gastroenterology Organisation (WGO) and their memberships for distributing the questionnaires to their membership.

\section{Statement of Ethics}

Ethical approval was granted by the University of Otago, New Zealand Ethics Committee (D18/312).

\section{Conflict of Interest Statement}

R.B.G. - Speaker fees: AbbVie, Janssen, Ferring, and Zespri. Research grants: Zespri, AbbVie, and Pfizer. Advisory board: Zespri, AbbVie, and Janssen. A.M.M. - No disclosures of conflicts of interest. M.V. - Research support: Tillots, Ferring, and Genetic Analysis. Advisory Board: Genetic Analysis. D.T.R. - Research funding: Takeda. Consultant: AbbVie; Abgenomics; Allergan, Inc.; Arena Pharmaceuticals; Biomica; Bristol-Myers Squibb; Dizal Pharmaceuticals; Ferring Pharmaceuticals, Inc.; Genentech/ Roche; Janssen Pharmaceuticals; Lilly; Mahana Therapeutics; Medtronic; Merck \& Co., Inc.; Napo Pharmaceuticals; Pfizer; Prometheus Laboratories; Shire; Takeda; and Target PharmaSolutions, Inc. F.S. - Consultant, speaker, and grant recipient from Eurofarma, Ferring, Janssen, Pfizer, Takeda, and UCB. E.V.L. - Consultant: AbbVie, Allergan, Amgen, Boehringer Ingelheim, Bristol-Myers Squibb, Celgene, Celltrion Healthcare, Eli Lilly, Genentech, Gilead, Janssen, Pfizer, Takeda, and UCB Biopharma. Research support: AbbVie, Amgen, Bristol-Myers Squibb, Celgene, Genentech, Gilead, Janssen, Pfizer, Takeda, and UCB Biopharma. W.K. - No disclosures or conflicts of interest. C.T. - No disclosures or conflicts of interest. J.-F.C. reports receiving research grants from AbbVie, Janssen Pharmaceuticals, and Takeda; receiving payment for lectures from AbbVie, Amgen, Allergan, Inc., Ferring Pharmaceuticals, Shire, and Takeda; receiving consulting fees from AbbVie, Amgen, Arena Pharmaceuticals, Boehringer Ingelheim, Celgene Corporation, Celltrion, Eli Lilly, Enterome, Ferring 
Pharmaceuticals, Genentech, Janssen Pharmaceuticals, Landos, Ipsen, Medimmune, Merck, Novartis, Pfizer, Shire, Takeda, Tigenix, and Viela Bio; and hold stock options in Intestinal Biotech Development and Genfit. S.C.N. - Speaker fees: AbbVie, Janssen, Ferring, Takeda, and Tillots. Research grants: AbbVie and Ferring. G.A. - Research grants: AbbVie and MSD. Speaker fees: Janssen, Takeda, Ferring, MSD, and AbbVie. Consultancy fees: AbbVie, MSD, and Takeda. C.N.B. is supported in part by the Bingham Chair in Gastroenterology. He has been on advisory boards for AbbVie Canada, Ferring Canada, Janssen Canada, Shire Canada, Takeda Canada, and Pfizer Canada; consulted to Mylan Pharmaceuticals; has received educational grants from AbbVie Canada, Pfizer Canada, Shire Canada, Takeda Canada, and Janssen Cana$\mathrm{da}$; and has been on the speaker's panel for Janssen Canada, Medtronic Canada, Takeda Canada, and Shire Canada.

\section{Funding Sources}

No specific funding was obtained for this study.

\section{Author Contributions}

All authors made substantial contributions to (1) the conception and design of the study, acquisition of data, or analysis and interpretation of data; (2) drafting the article or revising it critically for important intellectual content; and (3) final approval of the version to be submitted.

\section{References}

1 Su HY, Gupta V, Day AS, Gearry RB. Rising incidence of inflammatory bowel disease in Canterbury, New Zealand. Inflamm Bowel Dis. 2016;22(9):2238-44.

2 Molodecky NA, Soon IS, Rabi DM, Ghali WA, Ferris M, Chernoff G, et al. Increasing incidence and prevalence of the inflammatory bowel diseases with time, based on systematic review. Gastroenterology. 2012;142(1):4654.e42.

3 Kaplan GG. The global burden of ibd: from 2015 to 2025. Nat Rev Gastroenterol Hepatol. 2015;12(12):720.

4 Ng SC, Shi HY, Hamidi N, Underwood FE, Tang W, Benchimol EI, et al. Worldwide incidence and prevalence of inflammatory bowel disease in the 21st century: a systematic review of population-based studies. Lancet. 2018;390(10114):2769-78.

5 Shi HY, Levy AN, Trivedi HD, Chan FKL, Ng SC, Ananthakrishnan AN. Ethnicity influences phenotype and outcomes in inflammatory bowel disease: a systematic review and metaanalysis of population-based studies. Clin Gastroenterol Hepatol. 2018;16(2):190-e11.
6 Dotson JL, Cho M, Bricker J, Kappelman MD, Chisolm DJ, Tomer G, et al. Race differences in initial presentation, early treatment, and 1-year outcomes of pediatric Crohn's disease: results from the ImproveCareNow network. Inflamm Bowel Dis. 2017;23(5): 767-74.

7 Bernstein CN, Eliakim A, Fedail S, Fried M, Gearry R, Goh KL, et al. World Gastroenterology Organisation global guidelines inflammatory bowel disease: update August 2015. J Clin Gastroenterol. 2016;50(10):803-18.

8 Bernstein CN, Fried M, Krabshuis JH, Cohen $\mathrm{H}$, Eliakim R, Fedail S, et al. World gastroenterology organization practice guidelines for the diagnosis and management of IBD in 2010. Inflamm Bowel Dis. 2010;16(1):112-24.

9 Rose KL, Sherman PM, Cooke-Lauder J, Mawani M, Benchimol EI, Kaplan GG, et al. The impact of inflammatory bowel disease in Canada 2018: IBD research landscape in Canada. J Can Assoc Gastroenterol. 2019;2(Suppl 1):S81-91.

10 Grant A, Crane M, Laupacis A, Griffiths A, Burnett D, Hood A, et al. Engaging patients and caregivers in research for pediatric IBD: top 10 research priorities. J Pediatr Gastroenterol Nutr. 2019 Sep;69(3):317-23.

11 O'Sullivan A, Sheffrim SM. Economics: principles in action. Needham, Mass: Prentice Hall; 2003.

12 Ng SC, Tang W, Ching JY, Wong M, Chow $\mathrm{CM}$, Hui AJ, et al. Incidence and phenotype of inflammatory bowel disease based on results from the Asia-Pacific Crohn's and colitis epidemiology study. Gastroenterology. 2013; 145(1):158-e2.

13 Kedia S, Ahuja V. Epidemiology of inflammatory bowel disease in India: the great shift east. Inflamm Intest Dis. 2017;2(2):102-15.

14 Kotze PG, Underwood FE, Damiao A, Ferraz JGP, Saad-Hossne R, Toro M, et al. Progression of inflammatory bowel diseases throughout Latin America and the Caribbean: a systematic review. Clin Gastroenterol Hepatol. 2020 Feb;18(2):304-12.

15 Kappelman MD, Brenner EJ, Colombel JF, Ungaro R. Surveillance epidemiology of coronavirus under research exclusion (secureIBD) database. 2020. 